\title{
Reference Neutron Radiographs of Nuclear Reactor Fuel
}

\section{Domanus, Joseph Czeslaw}

Publication date:

1986

Document Version

Publisher's PDF, also known as Version of record

Link back to DTU Orbit

Citation (APA):

Domanus, J. C. (1986). Reference Neutron Radiographs of Nuclear Reactor Fuel. Risø National Laboratory. Risø-M No. 2575

\section{General rights}

Copyright and moral rights for the publications made accessible in the public portal are retained by the authors and/or other copyright owners and it is a condition of accessing publications that users recognise and abide by the legal requirements associated with these rights.

- Users may download and print one copy of any publication from the public portal for the purpose of private study or research.

- You may not further distribute the material or use it for any profit-making activity or commercial gain

- You may freely distribute the URL identifying the publication in the public portal

If you believe that this document breaches copyright please contact us providing details, and we will remove access to the work immediately and investigate your claim 
RISO-R-2575

REFERENCE NEUTRON RADIOGRAPHS OF NUCLEAR REACTOR FUEL

J. C. Domanus

Abstract. Reference neutron radiographs of nuclear reactor fuel were produced by the Euratom Neutron Radiography Working Group and published in 1984 by the Reidel Publishing Company.

In this collection a classification is given of the various neutron radiographic findings, that can occur in different parts of pelletized, annular and vibro-compacted nuclear fuel pins. Those parts of the pins are shown where changes of appearance differ from those for the parts as fabricated. AJso radiographs of those as fabricared parts are included.

The collection contains 158 neutron radiographs, reproduced on photographic paper (twice enlarged) and on duplicating film (original size).

INIS Descripters: CALIBRATION; DEPECTS; PUEL PINS; IMAGES; NEUTRON RADIOGRAPHY; STANDARDIZATION.

Accepted for presentation at the second World Conference on Neutron Radiography, Paris, 16-20.06-1986.

April 1986

Risø National Laboratory, DK-4000 Roskilde, Denmark 
ISBN $87-550-1219-1$

ISSN 0418-6435

Grafisk Service, Risø 1986 
coirrens

Page

1. ILTRODUCTION $\ldots \ldots \ldots \ldots \ldots \ldots \ldots \ldots \ldots \ldots \ldots \ldots \ldots \ldots \ldots \ldots . \ldots . \ldots$

2. WEAT THE REPEREACE RADIOGRAPES SHON ............. 5

3. PUEL PIN COAPONENTS $\ldots \ldots \ldots \ldots \ldots \ldots \ldots \ldots \ldots \ldots \ldots \ldots \ldots$

4. CLAssification of findimgs $\ldots \ldots \ldots \ldots \ldots \ldots \ldots \ldots \ldots \ldots \ldots$. 8

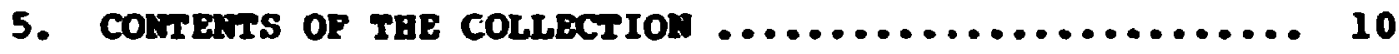

6. USE OR THE COLLECTIOA $\ldots \ldots \ldots \ldots \ldots \ldots \ldots \ldots \ldots \ldots \ldots \ldots \ldots \ldots$ II

7. TERHINOLOGT $\ldots \ldots \ldots \ldots \ldots \ldots \ldots \ldots \ldots \ldots \ldots \ldots \ldots \ldots \ldots \ldots \ldots . \ldots 11$

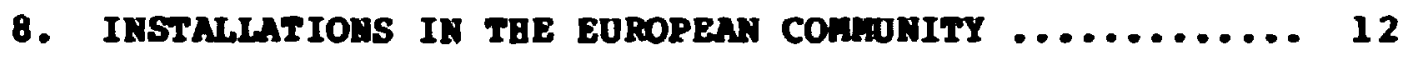
REPEREICES 



\section{INTRODUCTION}

sur weldings and castings many standard reference radiographs were published as AINI/F STM standards. Also the IIW has issued simijar collections of reference radiographs of welds. Therefore it was felt that a similar collection of standard reference raciographs will be needed in the field of neutron radiography of nuclear fuei. Thus the assessment of neutron radiographs of nuclear fuel elements can be faster and simpler if reference can be made tr. typical defects that can be revealed by neut ron radiography.

One of the first tasks of the Euratom Neutron Radiography working Group (NRWG), constituted in 1979, was to start standardization work by cstablishing a classification of defects revealeo by neutro. radiography of nuclear fuel and to collect adequate examples of corresponding neutron radiographs. Such a classification together with a collection of 36 neutron radiographs illustrating those defects was published in 1979 by Risø Natiunal Laboratory $|1|$ and was accepted by the NRWG as a first step in its standardization activity.

Just recently, a new edition was published of collection of reference neutron radiographs of neutron reactor fuel $|2|$. It contains 158 examples of defects in nuclear fuel as well as exampies of its different parts as fabricated, assembled from dif : rent neutron radicgraphy centers of the European communi$t y$, participating in the activities of the NRWG.

\section{WHAT THE REFERENCE RADIOGRAPHS SHOW}

It rust be mentioned that in the reference radiographs pub1 ished by ANSI/ASTM the term "discontinuity" is used, instead 
of "defect". The illustrations of those discontinuities are graded or ungraded and each graded discontinuity type has several severity levels.

In the IIw collection of reference radiographs the term "defect" is used, and the radiographs have been divided into grades, graded in accordance with the relative importance of the different types of defects.

In the present collection of reference neutron radiographs the term "defect" is used to designate a change in appearance shown on an original radiogranh of a particular part of the fuel as fabricated, to that show: on a subsequent radiograph, usually post-irradiation.

3. FUEL PIN COMPONENTS

In fig. I typical examples of nuclear fuel pins are given, containing pelletized, annular and vibro-compacted fuel.

The components of those pins are:

A. FUEL

A.a. Pellets

A.b. Annular fuel

A.c. Pellet-to-pellet-gap

A.d. Dishing

A.e. Vibro-compacted fuel

A.f. Puel-to-clad-gap

A.g. Fuel column

A.h. Puel composition

B. CLADDING
D. PLUGS

D.a. Bottom plug

D.b. Top plug

E. INSTRUMENTATION

E.a. Thermocouple

E.b. Pressure transducer

E.c. Diameter gauge

E.d. Lengtb gauge

g.e. Other instrumentation 
A.g) Fuel column

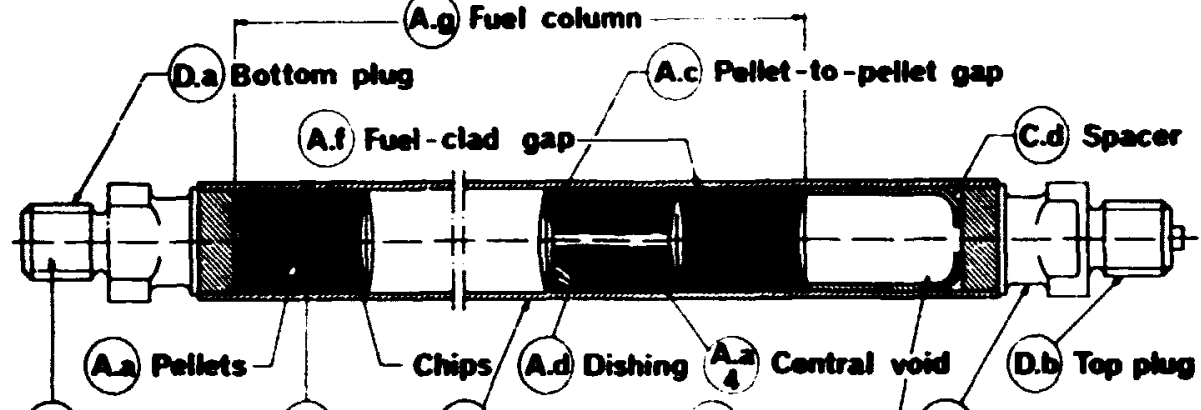

(D) plug (a) fuel (B) cladoning (c) plemim (D) plug

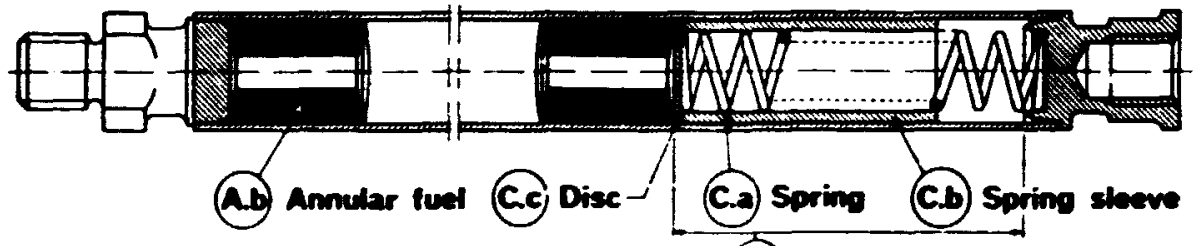

(C.) Tep of fuet cohmon to phes

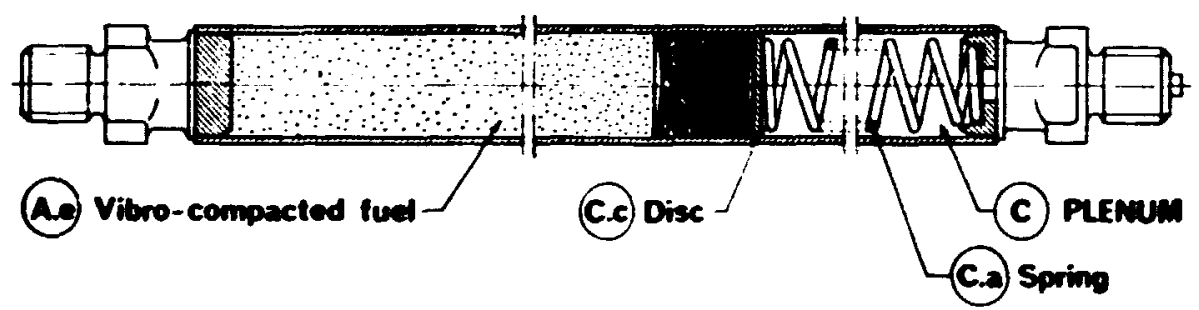

E.a) Thermocouple
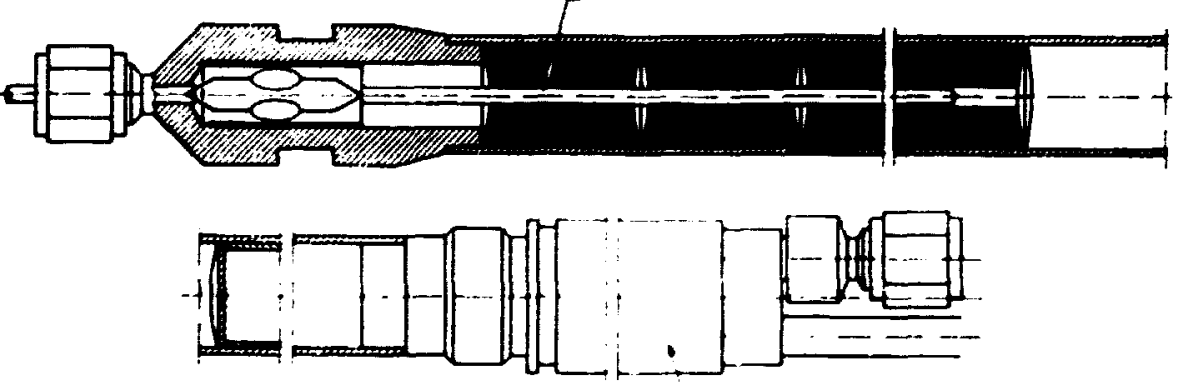

(E.b) Pressure transducer

Fig. 1. Nuclear fuel pins components 

C. PLENUM
C.a. spring
c.b. Spring sleeve
c.c. Insulating disc
C.d. Spacer
c.e. Fuel column to plug distance

\section{CLASSIFICATION OF FINDINGS}

All of the nuclear pin components 1 isted above are shown on the right side of fig. 2, whereas various differences in appearance from the fuel component as fabricated are listed at the top of fig. 2. They are the following:

0. (Fuel pin part) as fabricatro

3. CHANGE OR SAAPE OR LOCATION

1. CRACRS

3.1 Enlarged or swcllen

1.1 Random

3.2 Contracted

1.2 Longitudinal

3.3 Filled-up or closed

1.3 Transverse

3.4 Deformed

1.4 Annular

3.5 Broken

1.5 Stratified

3.6 Dislocated

3.7 Extended

2. CHIPS

3.8 Accumulated

2.1 Corner

3.9 Restructured

2.2 Other

3.10 Melted

2.3 In pellet-to-pellet gap

3.11 Disintegrated

2.4 Missing

3.12 Migrated

4. volaser

6. corrosion

4.1 In one pellet

6.1 Hydrides

4.2 Through several pellets

6.2 Oxides

4.3 Through whole fuel colum

6.3 Other 


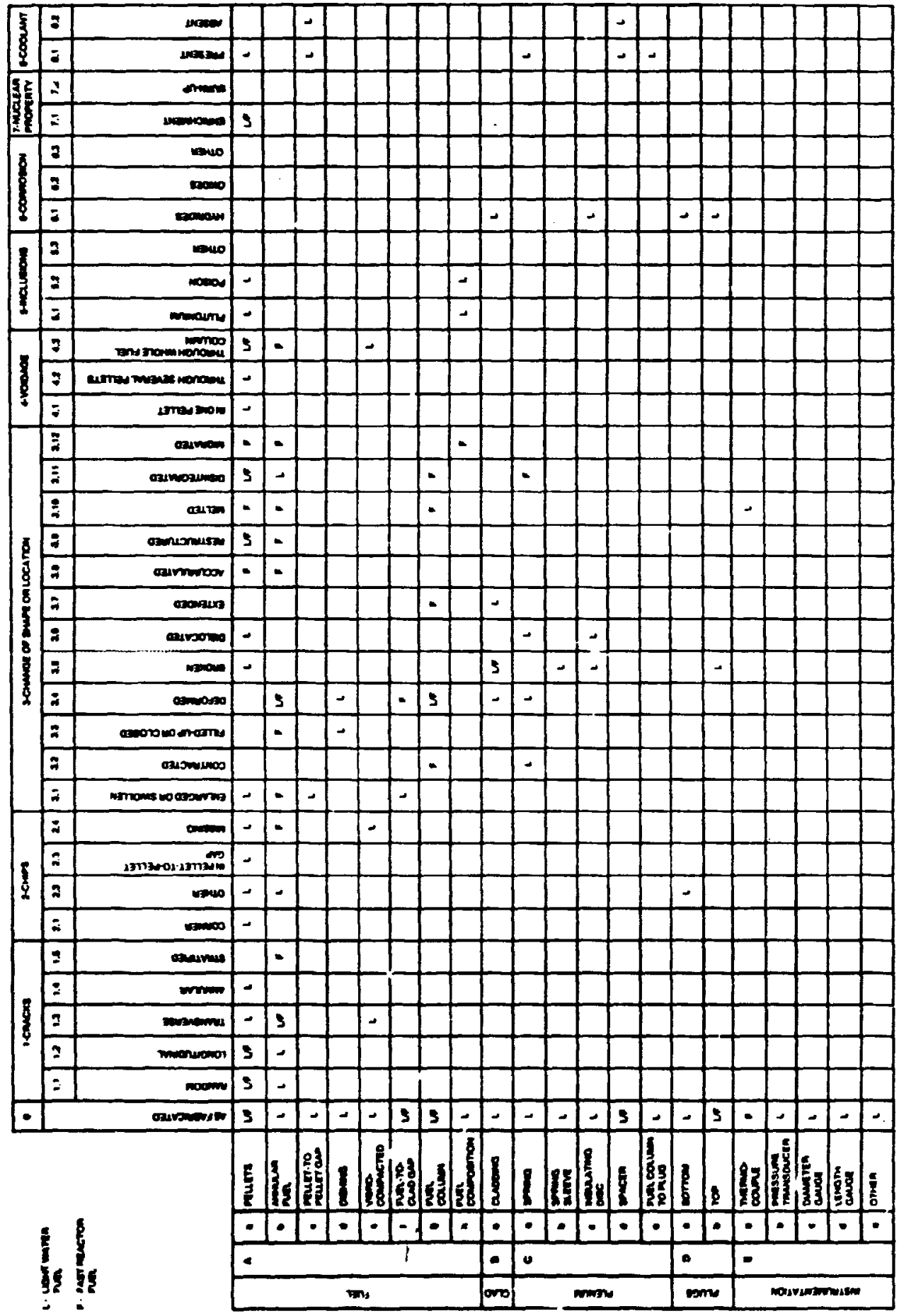

ت્1 
5. INCLUSIONS

5.1 Of plutonium

5.2 of poison

5.3 other
7. NUCLEAR PROPERTIES

7.1 Different enrichment

7.2 Different burnup

8. COOLANT

8.1 Present

8.2 Absent

As can be seen column "0" contains neutron radiographs of as fabricated fuel pin parts.

The neutron radiographic findings were selected from radiographs of light water (L) and fast (F) reactor fuel. If $L$ of $F$ is marked in fig 2 it means that in the collection $|2|$ an example is given. It does not, however, mean that there cannot be such a finding if neither $L$ nor $F$ marking occurs. It means only that none of the participants of the NRWG has found such an example among his radiographs.

\section{CONTENTS OP THE COLLECTION}

The collection of neutron radiographs of nuclear reactor fuel $|2|$ contains besides examples of nuclear pins components and a classification of neutron radiographic findings (described in 3 and 4 above) 158 copies and duplicating film (in original size) and on photographic paper (twice enlarged) of neutron radiographs taken on silver halide or nitrocellulose film.

A list of contents of the collection describes in detail the type of defect 111 ustrated on the radiographs, as well as the type of nuclear filel and the origin of the radiograph. 
6. USE OF THE COLLECTION

The copies of the neutron radiographs on film can be viewed without removing them by illuminating the blank page which follows with a shaded desk lamp.

The reference radiograph may also be removed from the collection and be viewed on an illuminator together with the actual radiograph under assessment.

\section{TERMINOLOGY}

The text of this collection is produced both in England and French. Special terms used throughout the collection, as well as some iseful ones in the field of neutron radiography, are reproduced in Danish, Dutch, English, French, German and Italian.

8. INSTALLATIONS IN THE EUROPEAN COMMUNITY

A survey on the main technical data and addresses of the neutron radiography installations in the European Community applicable for examination of nuclear reactor fuel is given at the end of the collection.

More technical detalls can be found in reference $|3|$. 


\section{REFERENCES}

Ill J. C. Domanus. Neutron radiographic findings in light water reactor fuel. Risø National Laboratory, Metallurgy Department, June 1979.

$|2|$ J. C. Domanus (editor). Reference : eutron radiographs of nuclear reactor fuel. D. Reider Publishing Co., 1984. EUR 8916 EN EP ISBN 90-277-1717-6.

|3| P. von der Harat, H. Rottger (editors). Neutron radiography handbook. D. Reidel Publishing Company, 1981, EUR 7622e, ISBN 90-277-1378-2. 


$$
\text { J. C. Domanus }
$$

Metallurgy

Group's own registration number ( $s$ )

Abstract

Refercnce neutron radiographs of nuclear reactor fuel were produced by the Euratom Neutron Radiography Working Group and published in 1984 by the Reidel Publishing Company.

In this collection a classification is given of the various neutron radiographic findings, that can occur in different parts of pelletized, annular and vivro-compacted nuclear fuel pins. Those parts of the pins are shown where changes of appearance differ from those for the parts as fabricated. Also radiographs of those as fabricated parts are included.

The collection contains 158 neutron radiographs, reproduced on photographic paper (twice enlarged and on duplicating film (original size).

Accepted for presentation at the second World Conference on Neutron Radiography, Paris, $16-20.06 .1986$.

Availaile on request from Ris\$ Library, Risø National Laboratory (Risø Bibliotek), Forsøganlag Risø), 